\title{
Application strategy of PiCCO in septic shock patients
}

\author{
XIAOYUN LIU, WENLI JI, JIFENG WANG and TAO PAN \\ Department of Intensive Care Medicine, Xiangyang Hospital Affiliated to Hubei University of Medicine, \\ Xiangyang, Hubei 441000, P.R. China
}

Received September 9, 2015; Accepted January 29, 2016

DOI: $10.3892 /$ etm.2016.3040

\begin{abstract}
Septic shock, also known as infectious or toxic shock, is a medical condition caused by severe infection and sepsis. Early identification, timely diagnosis and effective treatments are imperative to prevent this medical condition. The aim of the present study was to examine the application of pulse index continuous cardiac output (PiCCO) technique in the treatment of septic shock patients. Fifty septic shock patients were randomly divided into the conventional detection group (group $\mathrm{C}, \mathrm{n}=25$ ) and the $\mathrm{PiCCO}$ detection group (group $\mathrm{P}, \mathrm{n}=25$ ). A central venous catheter and radial artery catheter were placed into the patients of group $\mathrm{C}$ and a central venous catheter and PiCCO catheter (through femoral artery) were placed in the patients of group P to detect haemodynamics, which was managed and treated according to early goal-directed therapy (EGDT). PiCCO was applied to monitor and guide the application of fluid resuscitation, vasoconstriction drugs (dopamine) and positive inotropic drugs (dobutamine). The EGDT qualified rate of patients from the two groups at the 6th $\mathrm{h}$ of treatment, changes of post-resuscitation relevant parameters [blood lactate level, central venous oxygen saturation $\left(\mathrm{ScvO}_{2}\right)$, central venous pressure $(\mathrm{CVP})$, mean arterial pressure (MAP) and urine volume], positive fluid balance quantity and the dosage of dopamine and dobutamine at the 6th, 24th and 48th h were observed. In comparison to group C, group $\mathrm{P}$ showed an increase in the EGDT qualified rate and $\mathrm{ScvO}_{2}$ at the 6th h of treatment while the blood lactate level was decreased. The positive fluid balance quantity at the 6th and 24 th $\mathrm{h}$ and the dosage of dobutamine were increased while the dosage of dopamine was reduced $(\mathrm{P}<0.05)$. There was no statistical significance in terms of the differences of positive fluid balance quantity and the dosage of dopamine and dobutamine in the two groups at the 48th h of treatment $(\mathrm{P}>0.05)$. There was also no statistical significance in terms of the differences of CVP, MAP and urine volume in the two groups $(\mathrm{P}>0.05)$. In conclusion, under the monitoring and guidance of
\end{abstract}

Correspondence to: Dr Wenli Ji, Department of Intensive Care Medicine, Xiangyang Hospital Affiliated to Hubei University of Medicine, 15 Jiefang Road, Xiangyang, Hubei 441000, P.R. China E-mail: 1366346747@qq.com

Key words: pulse index continuous cardiac output, septic shock, early goal-directed therapy the PiCCO technique, EGDT treatment should be applied to septic shock patients together with early fluid resuscitation and positive inotropic drugs instead of using only vasoconstriction drug, which cause elevation of blood pressure.

\section{Introduction}

Septic shock also known as infectious or toxic shock, is a medical condition caused by severe infection and sepsis. Septic shock is primarily caused by pathogenic microbes or toxins, which originate from the interaction between foreign pathogenic microbes and the body's defense mechanism (1-3). The key factors that result in the development of septic shock include the pathogenicity of the microorganism, internal environment and immunogenicity of the human body. Those factors also play a role in multiple organ failure under toxic shock conditions (4-6). Early identification, timely diagnosis and effective therapeutic strategy are important measures in the treatment of septic shock.

Pulse index continuous cardiac output (PiCCO) is an efficient advanced haemodynamics monitoring system used in patients experiencing septic shock conditions in intensive care unit (ICU). It is a method applied to monitor haemodynamics in clinical practice and allows continuous haemodynamic monitoring using a large (femoral, brachial, or axillary) artery catheter and a central venous catheter (7). It fully reflects the changes of haemodynamic parameters, as well as cardiac systolic and diastolic functions. PiCCO is significant in terms of fluid resuscitation, fluid management, the application of diuretic and treatment evaluation (8).

The aim of the present study was to examine the application strategy of PiCCO in septic shock patients.

\section{Materials and methods}

Patients and diagnosis. A total of 50 septic shock patients admitted to the ICU of The First People's Hospital of Xiangyang (Xiangyang, China) between August 2012 and August 2013 were included in the present study. The patients included 29 men and 21 women, with an average age of 28-76 years. Initial diagnostic criteria were the presence of prominent signs of infection and symptoms of systemic inflammatory response syndrome. Fluid resuscitation treatment revealed that there were cases that could not be identified by these criteria. The cases had a systolic pressure of $<12.0 \mathrm{kPa}$, a reduction range of $>5.33 \mathrm{kPa}$ compared with the basal blood pressure 
value, and the mean arterial pressure (MAP) of $<8.00 \mathrm{kPa}$. Additionally, the tissue hypoperfusion symptom or the blood lactate was $>4 \mathrm{mmol} / \mathrm{l}$. Tracheal intubation was applied to all 50 patients and breathing machines (S9 Auto 25, ResMed, Sydney, Australia) were used to assist patients with breathing. The septic shock patients were equally divided into the PiCCO detection group (group $\mathrm{P}$ ) and conventional detection group (group C) based on the random number table method.

The present study was approved by the Medical Ethics Committee of the Xiangyang Hospital Affiliated to Hubei University of Medicine (Hubei, China). Written informed consent form was signed by family members of the patients.

Treatment methods. For group $\mathrm{C}$ or the conventional treatment method, a central venous catheter and radial artery catheter were placed into the patients to detect haemodynamics, which was managed and treated according to early goal-directed therapy (EGDT) (9). To perform fluid resuscitation patients with hypovolemia were transfused with $\geq 1,000 \mathrm{ml}$ crystalloid or $300-500 \mathrm{ml}$ of colloidal solution for the first $30 \mathrm{~min}$ until the central venous pressure (CVP) reached $1.07-1.60 \mathrm{kPa}$. During fluid resuscitation, vasoconstrictive drugs including norepinephrine or dopamine, were used to obtain a MAP of $\geq 8.66 \mathrm{kPa}$, with central venous oxygen saturation $\left(\mathrm{ScvO}_{2}\right)$ at $<70 \%$ and hematocrit (HCT) at $<30 \%$. Subsequently, red blood cells were transfused until HCT was $\geq 30 \%$. In the case that $\mathrm{ScvO}_{2}$ was $<70 \%$, positive inotropic drugs dobutamine or milrinone were applied until $\mathrm{ScvO}_{2}$ was $\leq 70 \%$.

For group $\mathrm{P}$, a central venous catheter and $\mathrm{PiCCO}$ catheter (through femoral artery) were placed into patients to detect haemodynamics, which was managed and treated according to EGDT. Fluid resuscitation was applied to patients suffering from hypovolemia [global enddiastolic volume index (GEDVI) $<680 \mathrm{ml} / \mathrm{m}^{-1}$, intrathoracic blood volume index (ITBVI) $<850 \mathrm{ml} / \mathrm{m}^{-1}$ and stroke volume variation (SVV) $\geq 10 \%$ ] until ITBVI was $\geq 850 \mathrm{ml} / \mathrm{m}^{-1}$, GEDVI $\geq 680 \mathrm{ml} / \mathrm{m}^{-1}$ and SVV $<10 \%$. During fluid resuscitation, vasoconstrictive drugs norepinephrine and dopamine were used when systemic vascular resistance index (SVRI) was $<1,200 \mathrm{dyns} / \mathrm{cm}^{-4} / \mathrm{m}^{-1}$ until MAP was $\geq 8.66 \mathrm{kPa}$. If SVRI was normal or increased and cardiac index (CI) continued to be reduced or if GEF and dPmx decreased, then positive inotropic drugs dobutamine or milrinone were applied until the CI was $<3.3 \mathrm{l} / \mathrm{min}$. Thus, $\mathrm{ScvO}_{2}$ was $<70 \%$ and HCT was $<30 \%$. Subsequently, red blood cells were transfused until HCT was $\geq 30 \%$.

Treatments were applied with the aim of patients achieving early resuscitation within $6 \mathrm{~h}$, with CVP of $1.07-1.60 \mathrm{kPa}$, systolic pressure $>12.0 \mathrm{kPa}$ and $\mathrm{MAP} \geq 8.66 \mathrm{kPa}$, urine volume $\geq 0.5 \mathrm{ml} / \mathrm{kg} / \mathrm{h}$, of $\mathrm{ScvO}_{2} \geq 65 \%$.

Observation items. EGDT qualified rate and changes of relevant parameters (blood lactate level, $\mathrm{ScvO}_{2}, \mathrm{CVP}$, MAP and urine volume) following resuscitation of patients from the two groups at the 6th $h$ of treatment were observed and recorded. The positive fluid balance quantity and the dosage of dopamine and dobutamine at the 6th, 24th and 48th $\mathrm{h}$ were observed and recorded.

Statistical analysis. The SPSS 17.0 software (SPSS, Inc., Chicago, IL, USA) was used for statistical data analysis. Data were presented as mean \pm standard deviation. The t-test was used for comparisons between the groups. A comparison of enumeration data was made using the $\chi^{2}$ test. $\mathrm{P}<0.05$ was considered to indicate a statistically significant difference.

\section{Results}

Comparison of general information of patients. Table I shows a comparison of the general information of patients included in the two groups. No statistical significant difference regarding patient characteristics between the two groups was identified (mean $\mathrm{P}>0.05$ ).

Comparison of EGDT qualified rate and changes of blood lactate level, $\mathrm{ScvO}$, CVP, MAP and urine volume of patients. A comparison was made of EGDT qualified rates and changes in the blood lactate level, $\mathrm{ScvO}_{2}, \mathrm{CVP}, \mathrm{MAP}$ and the urine volume of patients from the two groups at the 6th $\mathrm{h}$ of treatment (Table II). In comparison to group C, group P showed an increase in the EGDT qualified rate and $\mathrm{ScvO}_{2}$ at the 6th $\mathrm{h}$ of treatment while the blood lactate level was decreased (mean, $\mathrm{P}<0.05)$. No statistical significance in terms of the differences between CVP, MAP and urine volume in the two groups was identified (mean, $\mathrm{P}>0.05$ ) (Table II).

Comparison of positive fluid balance quantity and the dosage of dopamine and dobutamine. A comparison was made of the positive fluid balance quantity and the dosage of dopamine and dobutamine at the 6th, 24th and 48th $\mathrm{h}$ between the two groups (Table III). In comparison to group $\mathrm{C}$, the patients in group $\mathrm{P}$ showed a positive fluid balance quantity. The dosage for dobutamine was increased while the dosage for dopamine was reduced (mean, $\mathrm{P}<0.05$ ) at the 6th and 24th $\mathrm{h}$ of treatment. There was no statistically significant difference among the indicators at the 48 th $\mathrm{h}$ of treatment (mean, $\mathrm{P}>0.05$ ) (Table III).

\section{Discussion}

Among the different causes for multiple organ dysfunction syndrome (10), severe sepsis and septic shock are important reasons for the mortality of critically ill patients in the ICU. Severe sepsis and septic shock patients are subject to absolute or a relative lack of effective circulating blood volume, leading to hemodynamic instability (11). Therefore, positive fluid resuscitation is critical in the treatment of patients with severe sepsis and septic shock. EGDT program proposed by Rivers et al (12) focused on rapid expansion in order to increase cardiac output and oxygen flow, recover circulating blood volume immediately and reduce the time of hypoperfusion in tissues and organs. The aim of the EGDT program is to assist patient resuscitation within $6 \mathrm{~h}$ when septic shock initially occurs. Thus, patient mortality and the incidence rate of multiple organ dysfunction under the EGDT program is decreased.

PiCCO is a relatively new monitoring technique for minimally invasive haemodynamics that combines the lung heat dilution method and arterial pulse waveform technique, achieving the purposes of continuously monitoring parameters such as cardiac output, intrathoracic blood volume, GEDV, extravascular lung water, contractility index of 
Table I. Comparison of general information of patients in the two groups.

\begin{tabular}{|c|c|c|c|c|c|c|c|c|c|}
\hline \multirow[b]{2}{*}{ Group } & \multirow[b]{2}{*}{ No. } & \multirow[b]{2}{*}{$\begin{array}{c}\text { Age }(\text { mean } \pm S D) / \\
\text { years old }\end{array}$} & \multicolumn{2}{|c|}{ Gender/cases } & \multirow[b]{2}{*}{$\begin{array}{l}\text { APACHE II grade } \\
(\text { mean } \pm \text { SD }) / \text { grade }\end{array}$} & \multicolumn{4}{|c|}{ Types of primary diseases/cases } \\
\hline & & & Male & Female & & $\begin{array}{c}\text { Severe } \\
\text { pneumonia }\end{array}$ & $\begin{array}{c}\text { Severe } \\
\text { pancreatitis }\end{array}$ & $\begin{array}{c}\text { Postoperative } \\
\text { infection }\end{array}$ & $\begin{array}{c}\text { Digestive tract } \\
\text { perforation }\end{array}$ \\
\hline $\mathrm{C}$ & 25 & $45.7 \pm 8.9$ & 15 & 10 & $17.5 \pm 5.4$ & 8 & 6 & 5 & 6 \\
\hline $\mathrm{P}$ & 25 & $46.3 \pm 7.9$ & 14 & 11 & $19.4 \pm 6.7$ & 6 & 7 & 7 & 5 \\
\hline
\end{tabular}

$\mathrm{SD}$, standard deviation.

Table II. Comparison of EGDT qualified rate and changes of blood lactate level, $\mathrm{ScvO}_{2}, \mathrm{CVP}, \mathrm{MAP}$ and urine volume of patients from the two groups at the 6 th $\mathrm{h}$ of treatment (mean $\pm \mathrm{SD})$.

\begin{tabular}{|c|c|c|c|c|c|c|c|c|}
\hline Group & No. & $\begin{array}{l}\text { Treatment } \\
\text { time }\end{array}$ & $\begin{array}{l}\text { EGDT qualified } \\
\text { rate } / \%\end{array}$ & $\begin{array}{l}\mathrm{CVP} \\
\mathrm{P} / \mathrm{kPa}\end{array}$ & $\begin{array}{l}\mathrm{MAP} \\
\mathrm{P} / \mathrm{kPa}\end{array}$ & $\begin{array}{c}\text { Blood lactate } \\
\text { level } c /(\mathrm{mmol} / \mathrm{l})\end{array}$ & $\mathrm{ScvO}_{2} / \%$ & $\begin{array}{l}\text { Urine volume } \\
\qquad(\mathrm{ml} / \mathrm{kg} / \mathrm{h})\end{array}$ \\
\hline $\mathrm{C}$ & 25 & First $6 \mathrm{~h}$ & 64 & $\begin{array}{l}0.64 \pm 0.23 \\
1.53 \pm 0.25\end{array}$ & $\begin{array}{l}7.33 \pm 1.20 \\
9.73 \pm 1.73\end{array}$ & $\begin{array}{l}5.4 \pm 3.4 \\
4.1 \pm 2.5\end{array}$ & $\begin{array}{l}57 \pm 11 \\
64 \pm 10\end{array}$ & $\begin{array}{l}0.34 \pm 0.19 \\
0.71 \pm 0.26\end{array}$ \\
\hline $\mathrm{P}$ & 25 & First $6 \mathrm{~h}$ & $84^{\mathrm{a}}$ & $\begin{array}{l}0.67 \pm 0.24 \\
1.44 \pm 0.32\end{array}$ & $\begin{array}{l}7.20 \pm 1.07 \\
9.60 \pm 1.47\end{array}$ & $\begin{array}{l}5.5 \pm 3.6 \\
2.8 \pm 1.8^{\mathrm{a}}\end{array}$ & $\begin{array}{l}60 \pm 12 \\
72 \pm 9^{\mathrm{a}}\end{array}$ & $\begin{array}{l}0.32 \pm 0.22 \\
0.66 \pm 0.32\end{array}$ \\
\hline
\end{tabular}

${ }^{\mathrm{a}} \mathrm{P}<0.05$ compared with that in group $\mathrm{C}$ at the 6 th $\mathrm{h}$ of treatment. EGDT, early goal-directed therapy; CVP, central venous pressure; MAP, mean arterial pressure; $\mathrm{ScvO}_{2}$, central venous oxygen saturation; $\mathrm{SD}$, standard deviation.

Table III. Comparison of positive fluid balance quantity and the dosage of dopamine and dobutamine at the 6th, 24th and 48th $\mathrm{h}$ between the two groups (mean $\pm \mathrm{SD}$ ).

\begin{tabular}{|c|c|c|c|c|c|}
\hline Group & No. of patients & $\begin{array}{l}\text { Treatment } \\
\text { time, } \mathrm{h}\end{array}$ & $\begin{array}{l}\text { Positive fluid balance } \\
\text { quantity, V/Ml }\end{array}$ & $\begin{array}{l}\text { Dosage of dobutamine, } \\
\mathrm{m} / \mathrm{mg}\end{array}$ & $\begin{array}{l}\text { Dosage of dopamine, } \\
\mathrm{m} / \mathrm{mg}\end{array}$ \\
\hline \multirow[t]{3}{*}{$\mathrm{C}$} & \multirow[t]{3}{*}{25} & 6 & $3.542 \pm 618$ & $112 \pm 25$ & $239 \pm 42$ \\
\hline & & 24 & $6.147 \pm 1.018$ & $486 \pm 97$ & $846 \pm 148$ \\
\hline & & 48 & $8.427 \pm 1.328$ & $884 \pm 219$ & $994 \pm 249$ \\
\hline \multirow[t]{3}{*}{$\mathrm{P}$} & \multirow[t]{3}{*}{25} & 6 & $4.165 \pm 539$ & $179 \pm 39$ & $159 \pm 37$ \\
\hline & & 24 & $7.428 \pm 1.086$ & $634 \pm 118$ & $679 \pm 119$ \\
\hline & & 48 & $7.889 \pm 1.694$ & $858 \pm 225$ & $958 \pm 238$ \\
\hline
\end{tabular}

${ }^{*} \mathrm{P}<0.05$ is compared with that in group $\mathrm{C}$ at the 6th and 24 th $\mathrm{h}$ of treatment. SD, standard deviation.

left ventricular, peripheral vascular resistance and other parameters that reflect the changes of cardiac function and vascular resistance. Previous findings (13-16) have shown that compared with CVP, GEDVI and intrathoracic blood volume index provided by $\mathrm{PiCCO}$ reflect the cardiac preload more precisely and are able to better predict patient response to fluid resuscitation treatment. The results of the present study showed that in comparison to group C, the EGDT qualified rate and $\mathrm{ScvO}_{2}$ were increased while the blood lactate level was reduced at the 6 th $\mathrm{h}$ of treatment in group $\mathrm{P}$ (mean, $\mathrm{P}<0.05$ ). No statistically significant differences in CVP, MAP and the urine volume between the two groups were identified (mean $\mathrm{P}>0.05$ ) (Table II). It is crucial for the diagnosis and treatment of septic shock patients to identify and manage haemodynamics early and perform early fluid resuscitation because it can improve the EGDT qualified rate at the 6th $\mathrm{h}$ as well as unstable haemodynamics of septic shock patients (17-19).

Based on the EGDT program, the CVP is required to reach $\geq 1.07-1.60 \mathrm{kPa}$ within $6 \mathrm{~h}$. However, commonly used CVP in clinical practice is easily influenced by many factors, including the compliance of angiocarpy, intrathoracic pressure and mechanical ventilation, and therefore cannot accurately reflect cardiac preload condition (20). Usage of early goal-directed fluid resuscitation is imperative to maintain septic shock patient circulation relatively stable. Lack of fluid may cause hypoperfusion in tissues and the dysfunction of important organs such as brain and kidney. By contrast, 
extra fluid may exacerbate the situation since pulmonary edema and cardiac load are increased (21). Monitoring of haemodynamics and fluid volume is significant during the treatment of septic shock. Thus, any patients who experience severe sepsis and septic shock often suffer from severe circulation and respiratory dysfunction. Consequently, it is of important clinical significance to identify the reasonable fluid volume for each patient. Previous findings (12-25) have shown that early fluid resuscitation does not increase the risk of pulmonary edema for severe sepsis and septic shock patients, with no association with the types of fluid used in resuscitation. The results of the current study show that, compared with group $\mathrm{C}$, the positive fluid balance quantity at the 6th and 24th $\mathrm{h}$ and the dosage of dobutamine were increased while the dosage of dopamine was reduced (mean, $\mathrm{P}<0.05$ ). No statistical significance in terms of the differences in positive fluid balance quantity and the dosage of dobutamine and dopamine at the 48th $\mathrm{h}$ of treatment between the two groups was identified (mean, $\mathrm{P}>0.05$ ). It is therefore recommended that for septic shock patients under the guidance and monitoring of the PiCCO technique, early fluid resuscitation treatment and early use of positive inotropic drugs be employed instead of using only vasoconstriction drugs to maintain the stability of haemodynamics.

Septic shock is a type of distributive shock, and decreased systemic vascular resistance has been considered the first haemodynamic change for septic shock. Additionally, the decreasing range was significantly associated with the severity of septic shock and prognosis (26-28). If a large amount of fluid resuscitation is applied instead of using vasoactive agents within $6 \mathrm{~h}$, haemodynamic disorder cannot be altered to maintain blood pressure, resulting in exacerbation of ischemia and hypoxia of organs. The treatment guidelines of septic shock indicate that vasoconstriction drugs are to be applied within $6 \mathrm{~h}$ to guarantee blood perfusion in hypotension (29-31) in case of hypovolemia is not altered. Moderate systemic vascular resistance is considered useful to maintain tissue perfusion. However, excessive systemic vascular resistance may increase the load of left ventricular and then cause cardiac insufficiency. Systemic vascular resistance has been found to be increased in some septic shock patients (32). Kozieras et al (33) demonstrated that for septic shock patients, the intrathoracic blood volume may increase if the dosage of norepinephrine is added, indicating that there are interaction effects between systemic vascular resistance and cardiac preload. The current study shows that for group $\mathrm{P}$, for which the monitoring and guidance of PiCCO technique were applied, the dosages of the vasoconstriction drug dopamine at the 6th and 24 th $\mathrm{h}$ of treatment were reduced as compared to that in group $\mathrm{C}$ due to the early active fluid resuscitation treatment and use of positive inotropic drug (dobutamine). Therefore, through monitoring systemic vascular resistance and changes of MAP, PiCCO can guide the rational use of vasoactive agents and maintain the systemic vascular resistance within a normal range, which benefits septic shock patients.

In conclusion, under the monitoring and guidance of the PiCCO technique, the EGDT program, early fluid resuscitation and use of positive inotropic drugs are to be applied to septic shock patients instead of using only vasoconstriction drugs to increase blood pressure.

\section{References}

1. Liu W, Shan LP, Dong XS, Liu XW, Ma T and Liu Z: Effect of early fluid resuscitation on the lung in a rat model of lipopolysaccharide-induced septic shock. Eur Rev Med Pharmacol Sci 17: 161-169, 2013.

2. Yao Y, Zhiyong S and Hongyuan L: New cognition about definition and diagnosis of sepsis. Chin Crit Care Med 16: 321-324, 2004.

3. Kaplanski J, Nassar A, Sharon-Granit Y, Jabareen A, Kobal SL and Azab AN: Lithium attenuates lipopolysaccharide-induced hypothermia in rats. Eur Rev Med Pharmacol Sci 18: 1829-1837, 2014.

4. Moreira J: Severe sepsis and septic shock. N Engl J Med 369: 2063, 2013

5. Giovannelli A, Alessandri G, Rama A, Gandjbakhch I, Rondoni G and Alessandri N: A new completely flexible ring for mitral valve annuloplasty: the 'Rama-Valvuloplasty-Ring'. Five-year Pitié Salpétrière experience. Eur Rev Med Pharmacol Sci 12: 303-308, 2008.

6. King EG, Bauzá GJ, Mella JR and Remick DG: Pathophysiologic mechanisms in septic shock. Lab Invest 94: 4-12, 2014.

7. Antonini M, Meloncelli S, Dantimi C, Tosti S, Ciotti L and Gasparetto A: The PiCCO system with brachial-axillary artery access in hemodynamic monitoring during surgery of abdominal aortic aneurysm. Minerva Anestesiol 67: 447-456, 2001.

8. Lei M and Xiangyou Y: Development of clinical application of PiCCO system. J Chin Pract Diagn Ther 25: 3-5, 2011.

9. Pang T, Chen W, Lu ZM, Luo TH, Zhou H, Xue XC, Bi JW and Fang GE: Endothelial progenitor cells are influenced by serum of patients with systemic inflammatory response syndrome or multiple organ dysfunction. Eur Rev Med Pharmacol Sci 17: 3169-3177, 2013.

10. Chen W, Wang J, Feng QL, Xu SC, Xiang L, Feng LY, Chang ZL and $\mathrm{Ba} \mathrm{L}$ : The treatment of severe and multiple injuries in intensive care unit: report of 80 cases. Eur Rev Med Pharmacol Sci 18: 3797-3801, 2014.

11. Hu B1, Xiang H, Liang H, Yu L, Xu T, Yang JH, DU ZH and Li JG: Assessment effect of central venous pressure in fluid resuscitation in the patients with shock: a multi-center retrospective research. Chin Med J (Engl) 126: 1844-1849, 2013.

12. Rivers E, Nguyen B, Havstad S, Ressler J, Muzzin A, Knoblich B, Peterson E and Tomlanovich M; Early Goal-Directed Therapy Collaborative Group: Early goal-directed therapy in the treatment of severe sepsis and septic shock. N Engl J Med 345: 1368-1377, 2001.

13. Yoo JW, Moon JY, Hong SB, Lim CM, Koh Y and Huh JW: Clinical significance of circulating endothelial cells in patients with severe sepsis or septic shock. Infect Dis Lond 47: 393-398, 2015.

14. de Oliveira FS, Freitas FG, Ferreira EM, de Castro I, Bafi AT, de Azevedo LC and Machado FR: Positive fluid balance as a prognostic factor for mortality and acute kidney injury in severe sepsis and septic shock. J Crit Care 30: 97-101, 2015.

15. Macdonald SP, Arendts G, Fatovich DM and Brown SG: Comparison of PIRO, SOFA, and MEDS scores for predicting mortality in emergency department patients with severe sepsis and septic shock. Acad Emerg Med 21: 1257-1263, 2014

16. Cheng H, Fan WZ, Wang SC, Liu ZH, Zang HL, Wang LZ, Liu HJ, Shen XH and Liang SQ: N-terminal pro-brain natriuretic peptide and cardiac troponin I for the prognostic utility in elderly patients with severe sepsis or septic shock in intensive care unit: a retrospective study. J Crit Care 30: 654.e9-654.e14, 2015.

17. Vazquez-Guillamet C, Scolari M, Zilberberg MD, Shorr AF, Micek ST and Kollef M: Using the number needed to treat to assess appropriate antimicrobial therapy as a determinant of outcome in severe sepsis and septic shock. Crit Care Med 42: 2342-2349, 2014.

18. Chang DW, Huynh R, Sandoval E, Han N, Coil CJ and Spellberg BJ: Volume of fluids administered during resuscitation for severe sepsis and septic shock and the development of the acute respiratory distress syndrome. J Crit Care 29: 1011-1015, 2014.

19. Keegan J and Wira CR III: Early identification and management of patients with severe sepsis and septic shock in the emergency department. Emerg Med Clin North Am 32: 759-776, 2014.

20. Mallat J, Meddour M, Durville E, Lemyze M, Pepy F, Temime J, Vangrunderbeeck N, Tronchon L, Thevenin D and Tavernier B: Decrease in pulse pressure and stroke volume variations after mini-fluid challenge accurately predicts fluid responsiveness. $\mathrm{Br}$ J Anaesth 115: 449-456, 2015 
21. Han SP, Wang GT, Zhang SS, Liu Q and Wang L:Pre-hospital emergency values of hypertonic-hyperonconic limited resuscitation for traumatic shock. J Biol Regul Homeost Agents 29: 841-846, 2015

22. Al Khalaf MS, Al Ehnidi FH, Al-Dorzi HM, Tamim HM, Abd-Aziz N, Tangiisuran B, Hassan Y and Arabi YM: Determinants of functional status among survivors of severe sepsis and septic shock: One-year follow-up. Ann Thorac Med 10: 132-136, 2015.

23. Alsolamy S, Al Salamah M, Al Thagafi M, Al-Dorzi HM, Marini AM, Aljerian N, Al-Enezi F, Al-Hunaidi F, Mahmoud AM, Alamry A, et al: Diagnostic accuracy of a screening electronic alert tool for severe sepsis and septic shock in the emergency department. BMC Med Inform Decis Mak 14: 105, 2014.

24. Drey M, Behnes M, Kob R, Lepiorz D, Hettwer S, Bollheimer C, Sieber CC, Bertsch $\mathrm{T}$ and Hoffmann U: C-terminal agrin fragment (CAF) reflects renal function in patients suffering from severe sepsis or septic shock. Clin Lab 61: 69-76, 2015.

25. Barletta JF: Histamine-2-receptor antagonist administration and gastrointestinal bleeding when used for stress ulcer prophylaxis in patients with severe sepsis or septic shock. Ann Pharmacother 48: 1276-1281, 2014.

26. Ahmed W, Memon JI, Rehmani R and Al Juhaiman A: Outcome of patients with acute kidney injury in severe sepsis and septic shock treated with early goal-directed therapy in an intensive care unit. Saudi J Kidney Dis Transpl 25: 544-551, 2014.
27. Mok K, Christian MD, Nelson S and Burry L: Time to Administration of Antibiotics among Inpatients with Severe Sepsis or Septic Shock. Can J Hosp Pharm 67: 213-219, 2014.

28. Dellinger RP, Levy MM, Carlet JM, Bion J, Parker MM, Jaeschke R, Reinhart K, Angus DC, Brun-Buisson C, Beale R, et al: Surviving Sepsis Campaign: international guidelines for management of severe sepsis and septic shock: 2008. Intensive Care Med 34: 17-60, 2008.

29. Zhang W, Tan Z and Huang W: Clinical guidance value of goal-directed treatment under picco technique for early septic shock. Int Med Health Guidance News 16: 1686-1690, 2010.

30. Donnino MW, Clardy P and Talmor D: A central venous pressure goal of 8-12 $\mathrm{mm} \mathrm{Hg}$ for all patients in septic shock. Crit Care Med 35: 1441, 2007.

31. Sarkar S, Kupfer Y and Tessler S: Goal-directed therapy for severe sepsis. N Engl J Med 346: 1025-1026, author reply 1025-1026, 2002.

32. Society of CriticalCare Medicine of Chinese Medical Association: Monitoring and Support Guidelines for Haemodynamics of Adult Patients Suffering from Severe Sepsis and Septic Shock. Chin J Emerg Med 16: 121-126, 2007.

33. Kozieras J, Thuemer O and Sakka SG: Influence of an acute increase in systemic vascular resistance on transpulmonary thermodilution-derived parameters in critically ill patients. Intensive Care Med 33: 1619-1623, 2007. 